Research Article

\title{
Evaluation of Antibacterial Activity and Cytotoxicity of Green Synthesized Silver Nanoparticles Using Scoparia Dulcis
}

\author{
Kalyani Khanra ${ }^{1}$, Sudipta Panja ${ }^{1}$, Indranil Choudhuri ${ }^{1}$, Anindita Chakraborty ${ }^{2}$, Nandan Bhattacharyya ${ }^{1}$ \\ ${ }^{1}$ Department of Biotechnology, Panskura Banamali College, Panskura RS, PIN 721152, Purba Medinipur, West Bengal, India \\ ${ }^{2}$ Radiation Biology Division,UGC-DAE CSR, Kolkata Centre, Sector III, LB-8, Bidhan Nagar, Kolkata 700098, India \\ C Corresponding author: E-mail: bhattacharyya_nandan@rediffmail.com
}

Received: Sept. 10, 2015; Accepted: Sept. 29, 2015; Published: Oct. 8, 2015.

Citation: Kalyani Khanra, Sudipta Panja, Indranil Choudhuri, Anindita Chakraborty and Nandan Bhattacharyya. Evaluation of Antibacterial Activity and Cytotoxicity of Green Synthesized Silver Nanoparticles Using Scoparia Dulcis. Nano Biomed. Eng. 2015, 7(3), I 28 - I 33.

DOI: 10.5101/nbe.v7i3.p128-133.

\begin{abstract}
Green synthesis of silver nanoparticles (AgNPs) is gaining momentum in the field of nano-research. Scoparia dulcis leaves were used as a reducing agent for the synthesis of silver nanoparticles from an aqueous solution of silver nitrate $\left(\mathrm{AgNO}_{3}\right)$. Synthesized $\mathrm{AgNPs}$ were characterized by UV-Vis spectroscopy, XRD, SEM with EDAX and TEM. UV-VIS surface plasmon resonance spectroscopy was observed at $430 \mathrm{~nm}$. XRD data depicts that the NPs are crystalline in nature. The EDAX data indicate that $63.76 \%$ presence of Ag metal. The TEM \& SEM results indicate that size of the AgNPs ranges from $15-25 \mathrm{~nm}$. The results also support that spherical shape of the nanoparticles. In addition, the NPs are in polydispersed condition. The antimicrobial activities indicate significant inhibition of the growth of three pathogenic bacteria such as Pseudomonas ariginosa, Bacillua subtillis and Staphylococcus aureous. Cytotoxicity of this nanoparticle showed that this Ag-NP also has more cytotoxic effect on a lung cancer cell line, A549 cells compared to ovarian cancer cell line, PA1 indicating a possible therapeutic use of this AgNP.
\end{abstract}

Keywords: Silver nanoparticles; Green Silver nanoperticle synthesis; Plant extract; Antimicrobial activity; cytotoxicity assay

\section{Introduction}

Silver nanoparticles (AgNPs) have significant applications in aspects of human lifestyle ranging from cosmetics, agriculture, medicine drug delivery, electronics etc [1-6]. The major routes for biosynthesis of nanoparticles comprise of various physical, chemical and biological methods [7-11]. AgNPs synthesized using physical and chemical routes are less biocompatible and costly than biological methods. These physical methods also involve the use of toxic and hazardous solvents and chemicals that are toxic to environment. So now a days Biological routes for AgNPs synthesis have been gaining the attention of researchers as it overcomes the shortcomings of physical and chemical processes.

Scoparia dulcis Linn, family Scrophulariaceae, a herb found in every part of the globe has been used traditionally as a remedy for diabetes mellitus, hypertension, stomach troubles, hypertension, inflammation, bronchitis, hemorrhoids and hepatosis 
and as analgesic, antipyretic [12]. Hence this plant got special focus to the researchers. The modern research reveals this herb as a host of several active phytochemicals including saponin, tannins, amino acids flavonoides, terpenoids and catecholamine etc. [13] and it has several medicinal benefits [14, 15]. These phytochemicals function as both the reducing and stabilizing agents [16]. In the context of current research, we synthesized silver nanoparticles in a costeffective, non-toxic, eco-friendly green synthesis way using Scoparia dulcis as reducing agent.

Another aspect of the current study was to check the antimicrobial efficacy of synthesized silver nanoparticle as antibacterial activity exhibited by silver has been reported in a range of studies. Besides the assessment of the risks of synthesized nanoparticle was checked assessing the toxicity against two different cancer cell line of different origin.

\section{Materials and methods}

\section{Materials}

Silver Nitrate $\left(\mathrm{AgNO}_{3}\right)$, Agar, Luria-Bertani (LB) medium, 3,4,5-Dimethylthiazol-2-yl-2-5diphenyltetrazolium bromide (MTT) was purchase from Himedia (Bangalore, India). All the chemicals used were of analytical reagent grade. The pure cultures of Staphylococcus aureus (MTCC No. 3160), Bacillus subtilis (MTCC No. 736), Pseudomonas aeruginosa (MTCC No. 4637) for antimicrobial studies were purchased from Microbial Type Culture Collection and Gene Bank (MTCC) facility, IMTECH, Chandigarh, India.

\section{Plant material and preparation of the Extract}

Scoparia dulcis $L$. whole plants were collected during the month of January from West Bengal, India (Fig. 1). Ten gms of Scoparia dulcis fresh leaves were thoroughly washed in sterile distilled water and were cut into small pieces. These pieces were surface sterilized by $1 \% \mathrm{NaOCl}$ for 30 section. and then washed with sterile distilled water (x3 time) and dried. It was then dispensed in $100 \mathrm{ml}$ of sterile distilled water and boiled for one hour at $90^{\circ} \mathrm{C}$. The extract was further filtered through Whatman No. 1 filter paper [17].

\section{Synthesis of Silver Nanoparticles}

Silver nitrate solution $\left(\mathrm{AgNO}_{3}\right)$ was prepared in

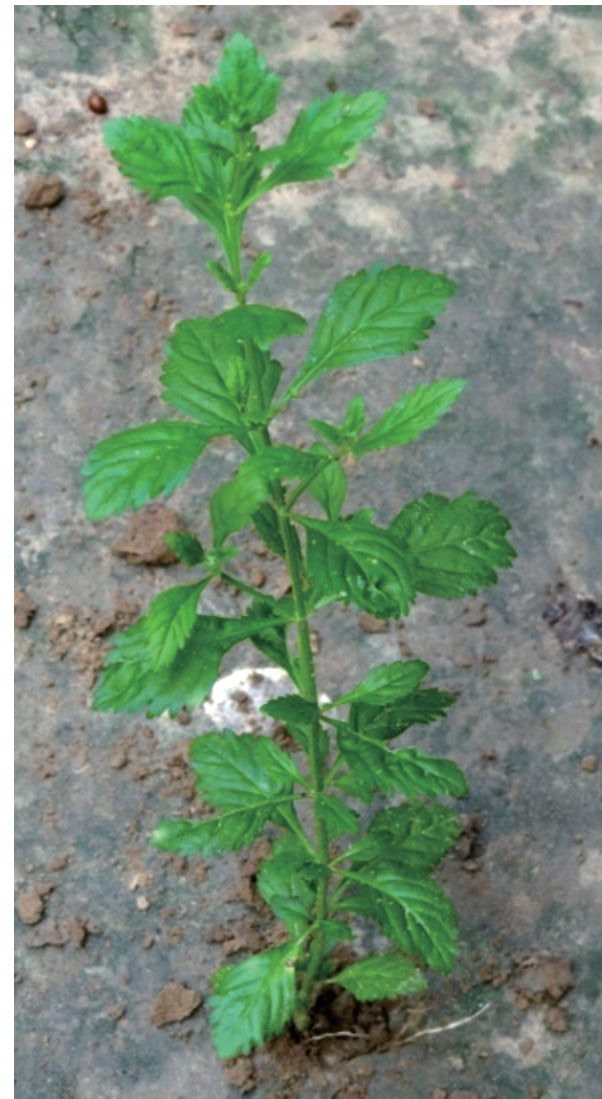

Fig. 1 Whole plant of Scoparia dulcis.

deionized water and used for the synthesis of silver nanoparticles. Ten $\mathrm{ml}$ of Scoparia dulcis leaf extract was added to $90 \mathrm{ml}$ of aqueous solution of $1 \mathrm{mM}$ silver nitrate and it was kept at water bath at $90^{\circ} \mathrm{C}$ for 1 hour to reduce silver ions [18]. The observed change in color from colorless to dark brown with time indicates the formation of AgNPs (Fig. 2).

\section{UV-VIS Spectroscopy analysis}

The reduction of pure $\mathrm{Ag}^{+}$ions was monitored by measuring the UV-Vis spectrum of the solution. UV-Vis spectral analysis was done by using UV-Vis spectrophotometer UV-2450 (Shimadzu) and scanning the spectra between $200-700 \mathrm{~nm}$ at the resolution of 1 nm.

\section{Characterization of silver nanoparticles}

\section{$X$-ray diffraction measurements}

The Ag-NPs of Scoparia dulcis were purified by repeated centrifugation at $15000 \mathrm{rpm}$ for $10 \mathrm{~min}$ and washing with deionized water to separate the AgNPs. The AgNPs were dried at $130^{\circ} \mathrm{C}$ overnight. The dried mixture of Ag-NPs was collected for the determination of the formation of Ag-NPs by an X'Pert Pro x-ray 


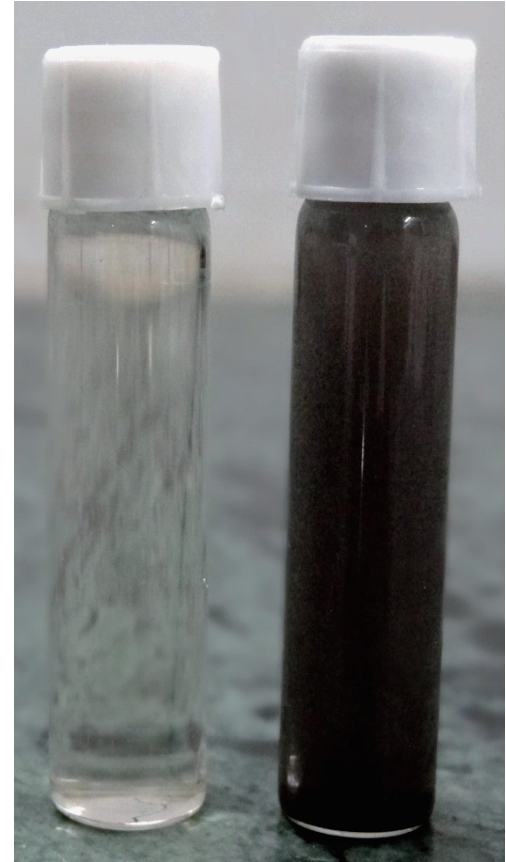

(a)

(b)

Fig. 2 (a) Preparation of Nanoparticle from leaf extract of Scoparia dulcis. Figure shows extract before (a) and after (b) exposure to silver nitrate.

diffractometer (PAN analytical BV, The Netherlands) operated at a voltage of $40 \mathrm{kV}$ and a current of $30 \mathrm{~mA}$ with $\mathrm{Cu} \mathrm{K} \alpha$ radiation and at a scan speed of $2 \mathrm{~nm}$ over the range of $2 \mathrm{q}$ values from $20^{\circ}$ to $80^{\circ}$.

\section{Transmission electron microscopy analysis (TEM) and EDX}

JEM-1400 (JEOL, USA) operating at $200 \mathrm{kV}$ was used for the study of morphology and size of AgNPs. Ag NPs were also subjected to energy dispersive X-ray analysis (EDX) [20].

\section{SEM analysis}

Nanoparticles of Scoparia dulcis were suspended in deionized water and used for SEM analysis by fabricating a drop of suspension into a clean electric stub and allowing water to completely evaporate. SEM observations were carried out on a ZEISS EVO 40 EP Electron microscope [21].

\section{Evaluation of antibacterial activity of $\mathbf{S}$ dulcis nanoparticles}

To detect the antibacterial activity of nanoparticle, three bacterial strains-Staphylococcus aureus Pseudomonas aeruginosa, and Bacillus subtilis, collected from MTCC-Chandigarh, were used. These strains were cultured according to their specifications [22].
Minimum inhibitory concentration of the antibiotic as well synthesized nanoparticle was evaluated as mentioned by Clinical and Laboratory Standard Institute (formerly known as National Committee for Clinically Laboratory Standards) [23, 24]. The overnight grown bacterial cultures of these three bacteria having approximately $105 \mathrm{CFU} \mathrm{ml}^{-1}$ were inoculated with silver nanoparticles, antibiotics. Synthesized Ag-NP and antibiotic were diluted to a final concentration of $0.19 \mu \mathrm{g} / \mathrm{ml}$. The discs containing AgNPs of different concentrations, and antibiotic were placed on the plates. The plates were incubated for 18 hour at $37^{\circ} \mathrm{C}$. Bactericidal activity with respect to zone of inhibition was also calculated using Antibiotic Zone scale (HIMEDIA). Each experiment was repeated at least 3 times. Ciprofloxacin was used as standard antibiotic for both the pathogenic microorganism.

\section{Cytotoxicity study on PA-1, and A549 cancer cell lines}

PA-1 is a cell line derived from human ovary teratocarcinoma, whereas A549 is human non-small cell lung alveolar epithelial cell line. These two cell lines were cultured in DMEM, 1\% penicillinstreptomycin, and 10\% FBS, pH 7.2. Cells were grown at $37^{\circ} \mathrm{C}$ in a humidified chamber containing $5 \% \mathrm{CO}_{2}$ $[25,26]$.

Cytotoxicity study was determined using the MTT assay [16]. Cells were seeded with equal density in each well of 96 well plates. Cells were then treated in 96-well plates with different concentrations $(1 \mu \mathrm{g} / \mathrm{ml}$ to $25 \mu \mathrm{g} / \mathrm{ml}$ ) of nanoparticles for 48 hours at $37^{\circ} \mathrm{C}$. At the end of the treatment period, MTT $(0.5 \%(\mathrm{w} / \mathrm{v})$ in phosphate-buffered saline was added to each well and the plates (set one) were incubated for another 4 hours at $37^{\circ} \mathrm{C}$. Purple colored insoluble formazan crystals in viable cells were dissolved using dimethyl sulfoxide (DMSO). Subsequently, the absorbance of the content of each well in each plate was measured at $567 \mathrm{~nm}$ using a multi-detection microplate reader.

\section{Statistical analysis}

All experiments were carried out in triplicate, and the results were expressed as the mean. Means and standard deviations (SD) were analysed.

\section{Results and discussion}

The observation of change of color of AgNPs from 
colorless to deep brown indicates the nanoparticles synthesis and it was further confirmed by UV-visible spectrum analysis. This physical appearance of the reaction due to the surface plasmon resonance (SPR) of the AgNPs is considered to be the primary signature of the formation of nanoparticles [27]. The UV-visible spectrum of the reaction mixture is shown in Fig. 3. A peak at $418 \mathrm{~nm}$ is assigned to the surface plasmon resonance band of the AgNP was observed. The broad centered peak assigned at $418 \mathrm{~nm}$ indicates slow reduction of silver ions to silver nanoparticles.

The suspension of the biosynthesized AgNps was centrifuged at $15000 \mathrm{rpm}$ for $10 \mathrm{~min}$ to separate the $\mathrm{AgNps}$ and washed with deionized water. It was dried overnight at $130^{\circ} \mathrm{C}$ in a hot air oven. These dried nanoparticles were used for XRD analysis. The powdered AgNPs were then drop coated and subjected to XRD analysis (JEOL), with $\mathrm{Cu}$ ka $1.5418 \mathrm{~A}$, voltage of $30 \mathrm{kV}$ and current at $20 \mathrm{~mA}$ and at a scan speed of $2 \mathrm{~nm}$ over the range of $2 \mathrm{~h}$ values from $20^{\circ} \mathrm{C}$ to $80^{\circ} \mathrm{C}$. The crystalline nature of biosynthesized silver nanostructure by Scoparia dulcis extract was further demonstrated and confirmed by the characteristic peaks observed in the XRD image at $\theta=38.35^{\circ}$ (111), $46.35^{\circ}(200), 64.45^{\circ}(220)$, and $76.83^{\circ}(311)$ and is

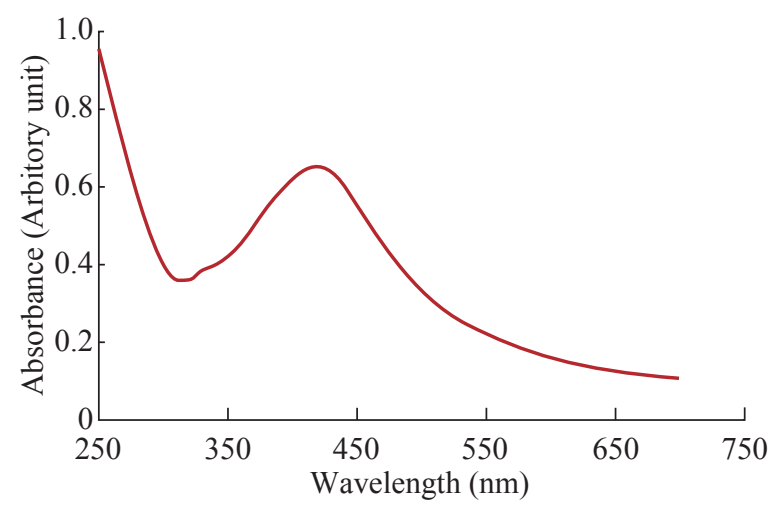

Fig. 3 UV-VIS spectral analysis of synthesized AgNPs. referred as Joint Committee on Powder Diffraction Standards (JCPDS) file no 03-0921 (Fig. 4). The Bragg reflections observed in the XRD pattern corresponding to these sets of lattice planes were observed which may be indexed as face-centered crystal structure of silver. The unassigned peaks could be due to the crystallization of bioorganic phase that occurs on the surface of the nanoparticles.

Scanning electron microscopy shows high-density Ag nanoparticles synthesized by $S$ dulcis plant extracts and further confirmed the presence of Ag nanoparticles. It was shown that relatively spherical in shape and is polydispersed without conglomeration in solution. The size of the AgNPs was found to be in the range of $15-25 \mathrm{~nm}$ (Fig. 5(a)). The EDS pattern indicates that $63.76 \%$ presence of Ag metal. The EDS spectrum also reveals $(\mathrm{O})$ peak which might be coming from the chamber of EDS (Fig. 5(b))

Transmission electron microscopy was used to investigate the structure and crystallinity of the AgNPs. It is clear from the high resolution TEM image (Fig.6(a)) that the AgNPs are spherical in shape. TEM images of AgNPs reveal the average mean size of 15$25 \mathrm{~nm}$ (Fig. 6(a)). The selected area electron diffraction (SAED) pattern (Fig. 6(b)) depicts polycrystalline

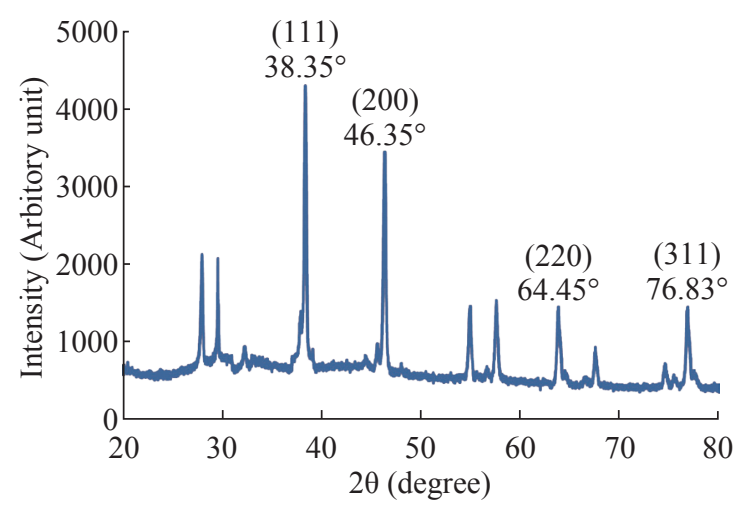

Fig. 4 XRD pattern of synthesized Ag-NPs.
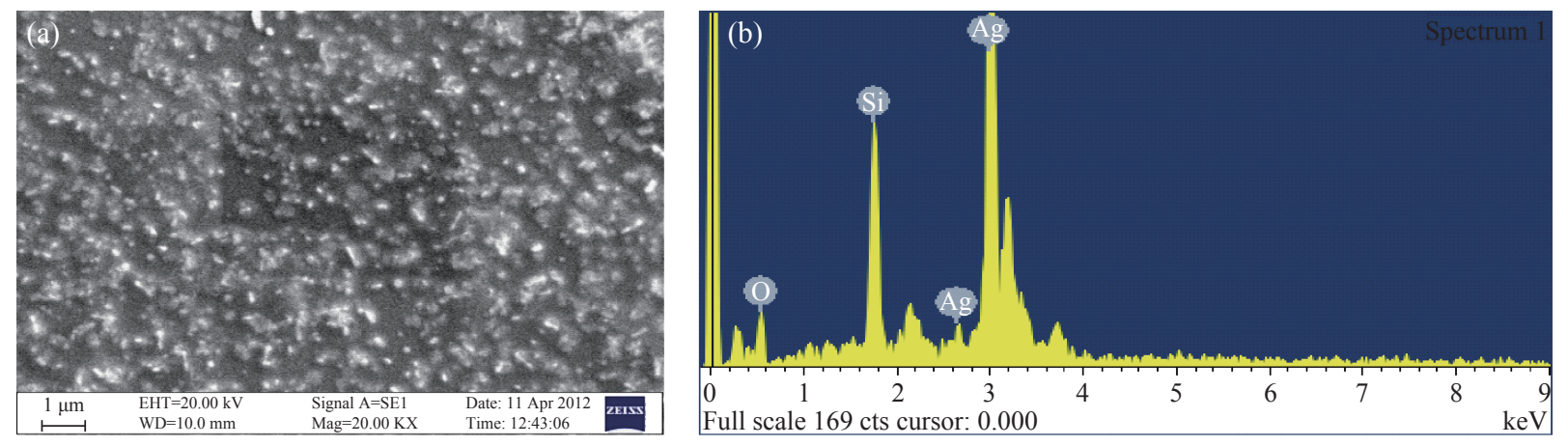

Fig. 5 (a) SEM image of the synthesized silver nanoparticles; (b) EDS analysis of synthesized AgNPs. 

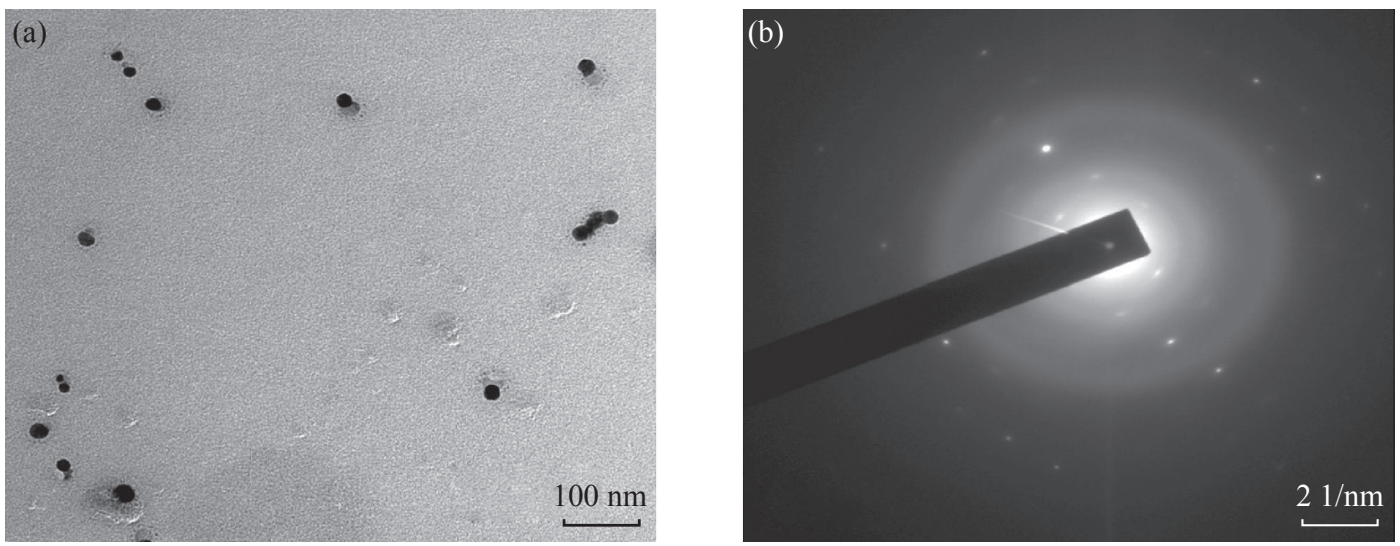

Fig. 6 (a) TEM image of the synthesized silver nanoparticles showing synthesis of polydispersed and spherical silver nanoparticles; (b) SAED pattern of major synthesized AgNPs.

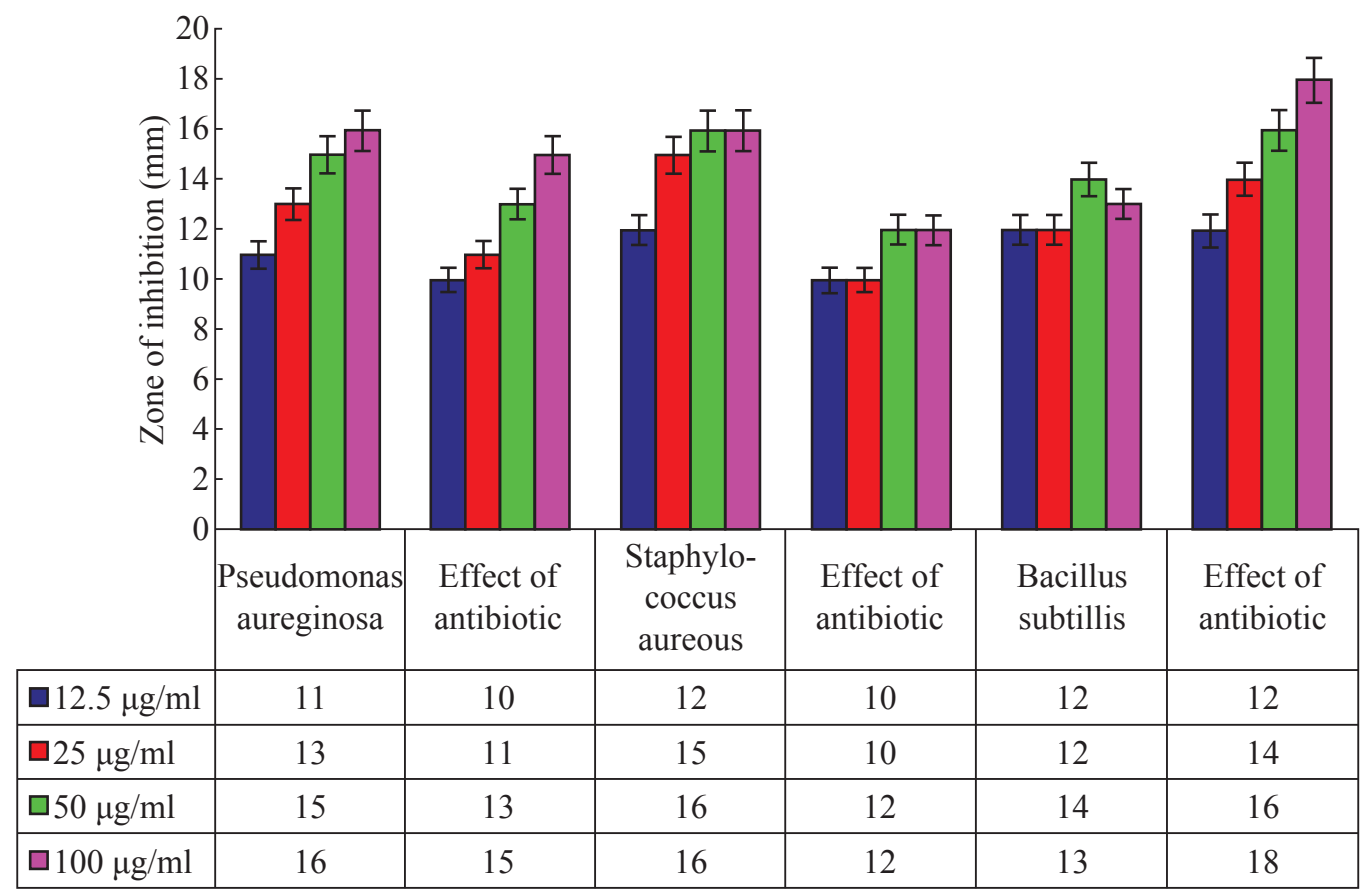

Fig. 7 Antibacterial activity analysis of synthesized AgNPs.

diffraction rings which indicate that these AgNPs are highly crystalline in nature.

The in vitro antimicrobial activity of AgNPs was studied against three pathogenic bacteria (Fig. 7). The ciprofloxacin control $(12.5-100 \mathrm{mg} / \mathrm{ml})$ exhibits zone of inhibition which ranges from $10-18 \mathrm{~mm}$. It was noticed that the synthesized AgNPs are active against all the three pathogens compared to control antibiotic (Fig. 7). For the biological synthesized nanoparticles minimum inhibition concentration is noted to be of same value $12.5 \mu \mathrm{g} / \mathrm{ml}$ for all tested microorganism.

Cytotoxicity assay indicate that AgNPs of $S$ dulcis exhibit a significant cytotoxicity on A549 cells compared to PA-1 cell line in a dose dependent manner. At $5 \mathrm{mg} / \mathrm{ml}$ of AgNPs concentration, 43.4\% A549 cells survived whereas at the same concentration, $70 \%$ PA-1 cells survived (Fig. 8). As the concentration of AgNPs increased, the anticancer efficacy also increased.

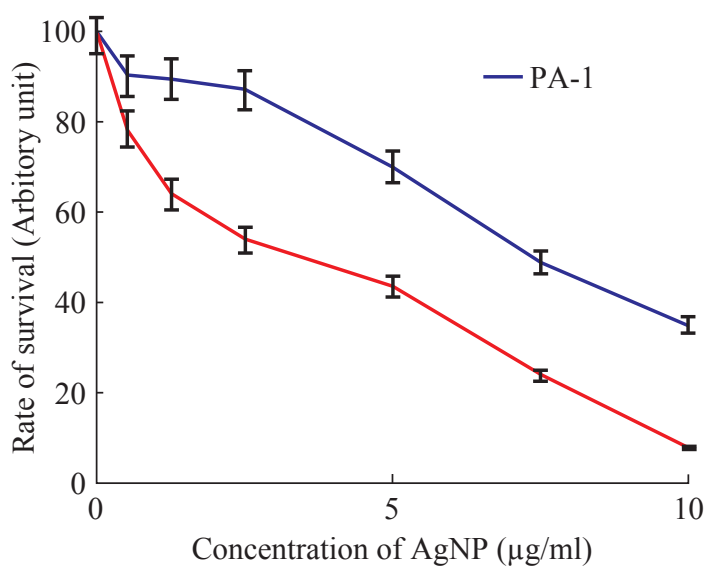

Fig. 8 Shows results for rate of survival of PA-1 and A549 cells treated with various concentrations of silver nanoparticles. 


\section{Conclusions}

In this report, a simple economically viable green method has been established to synthesize AgNPs using renewable $S$. dulcis plant material. The AgNPs were predominantly spherical with an average size of 15-25 nm in diameter. AgNPs has been shown to have antibacterial properties. This property has been used extensively for the prevention and treatment of different diseases. The green synthesized AgNPs showed potential antimicrobial property against human pathogens. The efficacy of nanoparticles in the killing of cancer cells was also tested. The results indicated that they are more effective in ovarian cancer cell line compared to lung cancer cell line. Hence, the AgNPs in combination with commercially available antibiotics may be used as an antimicrobial as well as anti cancer agent after trial on animals.

\section{References}

[1] X.L. Cheng, H. Zhao, L.H. Huo, et al., ZnO nanoparticulate thin film: preparation, characterization and gas-sensing properties. Sens. Actuators B, 2004, 102: 248-252.

[2] M. Rai, A. Yadav, A. Gade, et al., Silver nanoparticles as a new generation of antimicrobials. Biotechnol. Adv, 2009, 27: 76-83.

[3] S.S. Joshi, P.R. Patil, M.S. Naimase, et al., Role of ligands in the formation, phase stabilization, structural and magnetic properties of $\alpha-\mathrm{Fe}_{2} \mathrm{O}_{3}$ nanoparticles. $J$. Nanopart. Res, 2006, 5: 635-643.

[4] S. Kokura, O. Handa, T. Takagi, et al., Silver nanoparticles as a safe preservative for use in cosmetics. Nanomed. Nanotechnol. Biol. Med, 2010, 6: 570-574.

[5] O.V. Salata., Applications of nanoparticles in biology and medicine. J. Nanobiotechnol, 2004, 2: 3.

[6] N. Duran, P.D. Marcato, G.I. De Souza, et al., Antibacterial effect of silver nanoparticles produced by fungal process on textile fabrics and their effluent treatment. Journal Biomedical Nanotechnology, 2007, 3: 203-208.

[7] S.Y. Lee, E.S. Shim, H.S. Kang, et al., Fabrication of ZnO thin film diode using laser annealing. Thin Solid Films, 2005, 437: 31-34.

[8] A. Panacek, L. Kvitek, R. Prucek, et al., Silver colloid nanoparticles: synthesis, characterization, and their antibacterial activity. J. Phys. Chem. B, 2006, 110: 1624816253.

[9] Y. Lin, K.A. Watson, M.J. Fallbach, et al., Rapid, solventless, bulk preparation of metal nanoparticledecorated carbon nanotubes. Acs Nano, 2009, 3: 871-884.

[10] Y. Sun, Y. Xia, et al., Shape-controlled synthesis of gold and silver nanoparticles. Science, 2002, 298: 2176-2179.

[11] N. Vigneshwaran, N.M. Ashtaputre, P.V. Varadarajan, et al., Biological synthesis of silver nanoparticles using the fungus Aspergillus flavus. Mater. Lett, 2007, 61: 14131418 .
[12] H. Das, U. Chakraborty, et al., Anti-hyperglycemic effect of Scoparia dulcis in streptozotocin induced diabetes Research Journal of Pharmaceutical. Biological and Chemical Sciences, 2011, 2: 334-342.

[13] W.D. Ratnasooriya, J.R.A.C. Jayakody, G.A.S. Premakumara, et al., Antioxidant activity of water extract of Scoparia dulcis. Fitoterabia, 2005, 76: 220-222.

[14] K. Langeswaran, A. Jagadeesan, J. Vijayaprakash, et al., Hepatoprotective and Antioxidant activity of Scoparia dulcis Linn, against N-Nitrosodiethylamine (DEN) induced Hepatotoxicity in experimental Rats. Int. J. Drug Dev. \& Res, 2012, 4: 295-303.

[15] M. Rahmatullah, A. Chowdhury, R.T. Esha, et al., Ayurvedic influence on use of medicinal plants in Chakma traditional medicine. American-Eurasian Journal of Sustainable Agriculture, 2012, 6: 107-112.

[16] K. Murti, M. Panchal, P. Taya, et al., Pharmacological Properties of Scoparia Dulcis, A Review. Pharmacologia, 2012, 3: 344-347.

[17] G.V. White, P. Kerscher, R.M. Brown, et al., Green Synthesis of Robust, Biocompatible Silver Nanoparticles Using Garlic Extract. 2012.

[18] P. Jegadeeswaran, R. Shivaraj, R. Venckatesh, et al., Green synthesis of silver nanoparticles from extract of padina tetrastromatica leaf. Digest Journal of Nanomaterials and Biostructures, 2012, 7, 3: 991-998.

[19] E. Rafiee, S. Shahebrahimi, M. Feyzi, et al., Optimization of synthesis and characterization of nanosilica produced from rice husk (a common waste material). International Nano Letters, 2012, 2: 29.

[20] A. Devadiga, K.V. Shetty, M.B. Saidutta, et al., Timber industry waste-teak (Tectona grandis Linn.) leaf extract mediated synthesis of antibacterial silver nanoparticles. Int Nano Letter, 2015.

[21] S.S. Kumar, P. Venkateswarlu, V.R. Rao, et al., Synthesis, characterization and optical properties of zinc oxide nanoparticles. International Nano Letters, 2013, 3: 30.

[22] K.H. Cho, J.E. Park, T. Osaka, et al., The study of antimicrobial activity and preservative effects of nanosilver ingredient. Electrochim. Acta, 2005, 51: 956960.

[23] National Committee for Clinical Laboratory Standards (NCCLS). Methods for dilution antimicrobial susceptibility tests for bacteria that grow aerobically, M7A5. Pennsylvania: NCCLS; 2000.

[24] I. Sondi, B. Salopek-Sondi, et al., Silver nanoparticles as antimicrobial agent: A case study on E. coli as a model for Gram-negative bacteria. J Colloid Interface Sci, 2004, 275: 177-182.

[25] A. Roy, K. Khanra, A. Mishra, et al., International Journal of Advanced Research, 2013, 1: 193-198.

[26] K. Khanra, A. Roy, N. Bhattacharyya, et al., American J Nanoscience \& Nanotechnology Research, 2013, 1: 1-6.

[27] I. Johnson, J.H. Prabu, et al., Green synthesis and characterization of silver nanoparticles by leaf extracts of Cycas circinalis, Ficus amplissima, Commelina benghalensis and Lippia nodiflora. Int Nano Lett, 2015, 5: 43-51.

Copyright $\subset 2015$ Kalyani Khanra, Sudipta Panja, Indranil Choudhuri, Anindita Chakraborty and Nandan Bhattacharyya. This is an open-access article distributed under the terms of the Creative Commons Attribution License, which permits unrestricted use, distribution, and reproduction in any medium, provided the original author and source are credited. 